\title{
Techniques of low technology sampling of air pollution by metals: a comparison of concentrations and map patterns
}

\author{
O L L LLOYD, F A GAILEY
}

From the Environmental Epidemiology and Cancer Centre, Wolfson Institute of Occupational Health, Department of Community Medicine, University of Dundee, Ninewells, Dundee, UK

ABSTRACT During a 17 month survey of air pollution in the town of Armadale, central Scotlanit, the concentrations of some metals (iron, manganese, zinc, lead, copper, chrome, nickel, cadmiura, and cobalt) were measured in seven types of low technology sampler-four indigenous and three transplanted-at 47 sites. The geographical patterns of the concentrations in the samplers were compared on two types of map. For most metals, sites with high concentrations were present close to the foundry and also in the north of the town. The differences between the patterns of pollution shown by the various types of sampler probably reflected differing mechanisms for collection and different affinities for various sizes and types of metal particle.

During the late 1960s and for much of the 1970s, mortality from lung cancer and other diseases was exceptionally high in Armadale, a small industrial town in central Scotland. ${ }^{1-4}$ A cluster of deaths from lung cancer was found directly to the south west of the town's steel foundry, a source of local air pollution. ${ }^{56}$ Subsequent epidemiological inquiries failed to incriminate tobacco or occupational factors as major causes of the high mortality from lung cancer, ${ }^{7}$ and hence the possible contribution of industrial air pollution to these epidemiological findings merited further investigation.

When airborne metals are emitted from sources near ground level, their concentrations can change substantially over short distances. When such types of emission are investigated, a high density of sampling sites is necessary. ${ }^{8}$ In Armadale the low height of the major source of pollution and the significant clustering of lung cancer necessitated sampling techniques sufficiently inexpensive to allow the relative concentrations of metals in air near the height of human inhalation to be measured at many sites throughout the town. As well as providing information about current patterns including seasonal

Accepted 8 July 1986 fluctuations, the techniques were required to provid some indication of past patterns of pollution.

Samplers used in studies of atmospheric pollution fall into two major categories: high technology sam plers and low technology samplers. The use of high technology samplers in Armadale was precluded for several reasons: their tendency to break down whey exposed for long periods, the cost of monitoring numerous sites, the absence of power supplies at the peripheral areas of the town (battery power was. impractical because of the need to change the bat; teries frequently), and the lack of sites that were both secure and scientifically acceptable (high or inacces sible to minimise vandalism and sufficiently exposed to avoid the distortions caused by shelter but withot exposing the mechanical parts to bad weather).

Low technology samplers have different technic disadvantages, ${ }^{9}$ and their reputations are less valio dated by experience. Nevertheless, for Armadale the had important advantages: their low cost permitted high density of sampling sites and a long surve period; the deployment of several types of low tecte nology sampler allowed cross checking of results; thes use of indigenous samplers - that is, those already present in the fieldwork area-provided some indis cation of air pollution during preceding years; beint independent of a power supply and sufficiently incorf spicuous to minimise the risk of vandalism, transplan 
samplers could be placed at scientifically optimal sites for the survey; and most samplers could collect and retain metals even when environmental concentrations are exceptionally high, thereby making it unlikely that their collecting efficiencies became impaired through saturation by metals. For these reasons, it was decided to use these samplers for the survey in Armadale and to compare the resulting patterns of pollution by mapping techniques.

In an earlier part of the survey 47 sampling sites had been shown to provide adequate coverage for the town, ${ }^{10}$ with more sites per unit area assigned to the vicinity of the foundry and to the district of the town where the cluster of lung cancer had been found. ${ }^{11}$ The earlier studies had also identified the species of moss and lichen present in all parts of the town which could be used as indigenous samplers. Further preliminary work had also answered methodological problems such as the effects of sampler size and duration of exposure on their collection of metals and questions about their reliability. ${ }^{12-14}$

In the main survey using low technology samplers it was decided to deploy both indigenous and transplant samplers. The indigenous samplers were moss (Hypnum cupressiforme), lichen (Lecanora conizaeoides), grass (Agropyron repens), and surface soils. The transplant samplers were spherical nylon bags of acid washed Sphagnum moss (SMBs), small branches covered in the lichen Hypogymnia physodes, and small rectangles of a synthetic fabric called tak wrapped around plastic hair rollers. The properties, preparation, and deployment of these samplers have been described in detail elsewhere. ${ }^{11-19}$ In the present paper we compare the concentrations of various metals in the different types of sampler and discuss the resulting map patterns.

\section{Methods}

In the survey using indigenous materials composite samples of each type of sampler were collected from the 47 sites in Armadale in January 1981 (fig 1), as described above. ${ }^{11-19}$ The concentrations of iron $(\mathrm{Fe})$, manganese $(\mathrm{Mn})$, zinc $(\mathrm{Zn})$, lead $(\mathrm{Pb})$, copper $(\mathrm{Cu})$, chromium $(\mathrm{Cr})$, nickel $(\mathrm{Ni})$, cadmium $(\mathrm{Cd})$, and cobalt $(\mathrm{Co})$ in the samples were analysed by flame atomic absorption spectrophotometry.

The transplant survey, which lasted from May 1981 to October 1982, consisted of eight batches (exposures), each of which lasted two months (with the exception of the fourth batch which lasted three months because of adverse weather). At the same 47 sites that were used for the indigenous samplers, sampling heads were attached, at a height of $2 \mathrm{~m}$, to a bamboo pole. Each sampling head, which was a plastic coated wire loop, supported one example of each

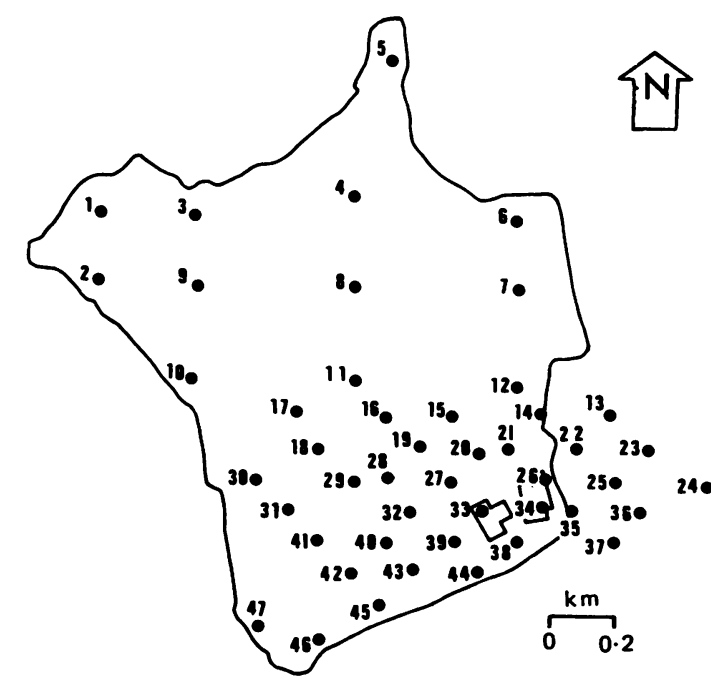

Fig 1 Positions of 47 sites in survey using low technology samplers in Armadale. Factory is located in south west corner of town.

type of transplant (fig 2). After exposure in the field, the concentrations of metals in the transplants were analysed following the procedure used for the indigenous samplers. The final values for the metals collected by the transplants were obtained by subtracting the concentrations in the unexposed samplers from those in the exposed ones.

To illustrate the concentrations of metals at individual sites throughout the town, grid maps were constructed using the Camgrid computer mapping package, with the range of each data set being divided into five equal intervals; only the maps for Fe and $\mathrm{Mn}$ (the conventional markers of the steel industry) and $\mathbf{C r}$ (used in special steel production) are presented in this paper. To indicate the probable flow of metallic pollution in the town, maps of the estimated concentrations of $\mathrm{Fe}, \mathrm{Mn}$, and $\mathrm{Cr}$ in the three transplants and Hypnum were constructed using the GLIM statistical computer package, which allows relative concentrations to be estimated for locations lacking samplers; contour bands contained letters of the alphabet corresponding to the relative concentrations of a metal within any one map, " $A$ " representing the lowest concentrations.

The mean concentrations of each metal for the whole town in the different types of sampler, and the related coefficients of variation, were compared. For this purpose, the minimum concentration of a given metal in the indigenous samplers at any site was taken as an approximation to the background concentration in that type of sampler and was subtracted 


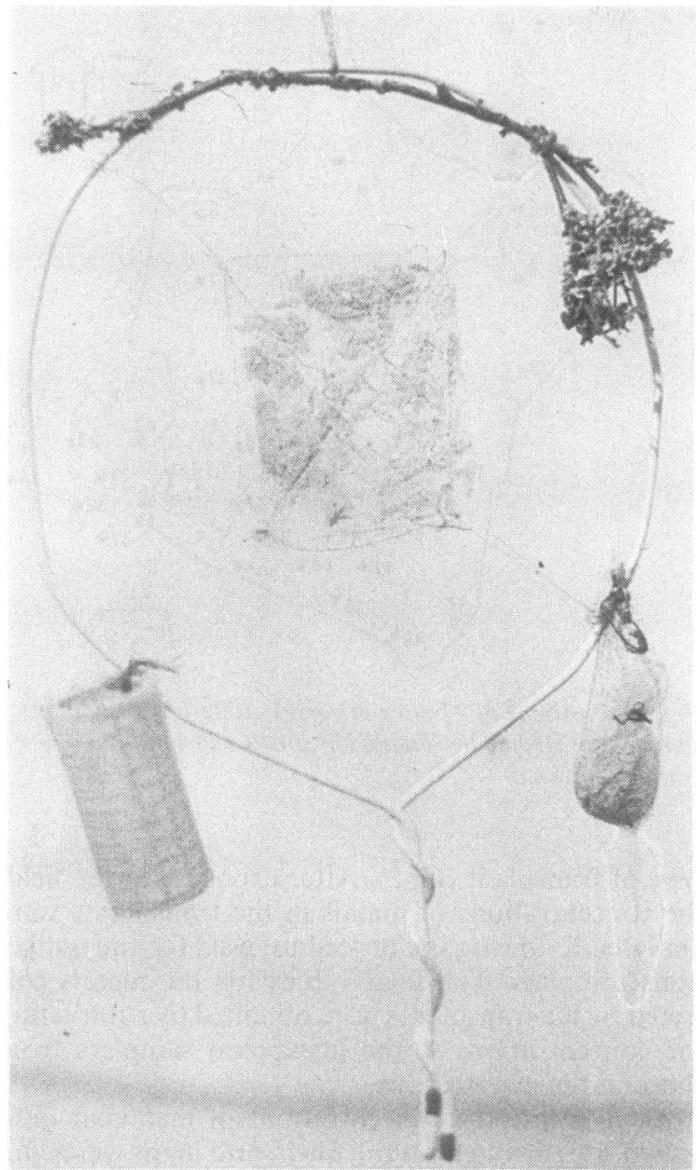

Fig 2 An example of a sampling head with different types of transplant sampler on circumference: spherical moss bag (SMB), tak fabric on hair roller, and Hypogymnia on twig (in centre is a vertical flat moss bag).

from the concentrations of that metal collected in the same type of sampler at each of the other sites. The resulting values were then compared with the values in the transplants, from which the background concentrations in the unexposed transplants had already been subtracted. Tak was not included in this comparison because its metal concentrations were in different units. ${ }^{16}$

\section{Results}

GRID MA PS (figs 3-5) (table)

In most of the samplers high concentrations of $\mathrm{Fe}$ were present in the south east quarter of the town. In soils, however, high values were found in most of the town including the south east, whereas in grass, the only site with a high value was to the east of the foundry. In the transplant samplers and in soils high values were also found in the town's north east $\mathrm{d}$ 䆑 trict. In all samplers except soils the intermediate values were interspersed between the high values in the town's south east quarter, often showing a nor east/south west orientation on either side of $t$ 留 foundry. In general, the patterns of the concea trations of $\mathrm{Fe}$ in the indigenous samplers were less comparable with each other than were the patterns in the transplants.

In the transplants the patterns for Mn generaldy resembled those of $\mathrm{Fe}$ in showing the high valuofs mainly in the town's south east quarter and north east district. In the indigenous samplers the positions of the few high concentrations of $\mathrm{Mn}$ were not consio tent: in Hypnum and Lecanora they were to the north and east of the foundry respectively, in grass theg encircled the foundry, and in soils they were dispersef throughout the town. The distribution of the intermediate values of $\mathrm{Mn}$ resembled that of $\mathrm{Fe}$ in all sareplers except soils.

Most of the patterns for $\mathrm{Zn}$ showed high concen. trations at only one site. In contrast to the indigenous samplers, where the positions of the highest deposition were not consistent, all transplants showed high values in the north east of the town, with tak arf Hypogymnia also having moderately high values neक्षा the foundry. The intermediate values in all sampless were again distributed around the foundry, soms times separated from it by a ring of low values.

In many of the samplers high and intermediate val ues of $\mathrm{Pb}$ were found only, or mainly, in the southen half of the town, particularly around the foundry. Hypnum, Lecanora, grass, and tak a few sites with intermediate concentrations were present in the northern half of the town.

The patterns of $\mathrm{Cu}$ resembled those of $\mathrm{Fe}$ in most samplers in Hypnum, Hypogymnia, and the SMBs. Lecanora, grass, and the soils the patterns were closer to those of $\mathrm{Zn}$. The pattern in tak was unreliables, being based on only three batches.

The higher values of $\mathrm{Cr}$ were near the foundry most samplers. In soils they were closer to the town centre; in Lecanora they were in the north of the tow

High and intermediate values of $\mathrm{Ni}$ were near the foundry in the indigenous samplers; in Hypnum and soils they extended to the town's centre.

The concentrations of the patterns of $\mathrm{Cd}$ in the indigenous samplers were low, and hence require ca政 tious interpretation. The highest values were gene ally close to the foundry, although high values were also found in the soils in the north east and north west of the town. In the only two samplers which collected Co, Hypnum, and soils the patterns resembled those of $\mathrm{Cd}$. 
Total ranges, divided into five equal intervals, of the concentrations of various metals (in $\mu \mathrm{g} / \mathrm{g}$ ) in the low technology samplers; the values are those at the top of each interval (the numbers of sites within each range are in parentheses). The intervals of the Co concentrations in Hypnum, and the numbers of sites in each interval, were: 4(16), 7(14), 10(4), 13(6), 16(7); in soils, the values were: $8(14), 12(16), 16(8), 20(7), 24(2)$

\begin{tabular}{|c|c|c|c|c|c|c|c|c|}
\hline Sampler & $\mathrm{Fe}$ & $M n$ & $Z n$ & $\mathrm{~Pb}$ & $\mathrm{Cu}$ & $\mathrm{Cr}$ & $N i$ & $C d$ \\
\hline Hypnum & $\begin{array}{l}2345(17) \\
2690(6) \\
3035(3) \\
3380(13) \\
3725(8)\end{array}$ & $\begin{array}{l}237(18) \\
386(27) \\
536(1) \\
685(0) \\
835(1)\end{array}$ & $\begin{array}{l}140(33) \\
237(9) \\
334(3) \\
430(1) \\
530(1)\end{array}$ & $\begin{array}{c}83(4) \\
136(9) \\
189(11) \\
243(10) \\
296(13)\end{array}$ & $\begin{array}{l}130(37) \\
248(1) \\
365(7) \\
483(0) \\
600(2)\end{array}$ & $\begin{array}{l}24(10) \\
36(12) \\
47(7) \\
58(10) \\
69(8)\end{array}$ & $\begin{array}{l}21(18) \\
30(17) \\
38(7) \\
42(1) \\
54(4)\end{array}$ & $\begin{array}{l}1 \cdot 8(11) \\
2 \cdot 4(22) \\
3 \cdot 0(9) \\
3 \cdot 6(3) \\
4 \cdot 0(2)\end{array}$ \\
\hline Lecanora & $\begin{array}{l}1111(10) \\
2067(14) \\
3022(13) \\
3978(4) \\
4934(6)\end{array}$ & $\begin{array}{l}67(38) \\
133(7) \\
200(1) \\
266(0) \\
333(1)\end{array}$ & $\begin{array}{l}133(40) \\
259(4) \\
387(2) \\
514(0) \\
461(1)\end{array}$ & $\begin{array}{l}69(28) \\
138(11) \\
206(4) \\
275(1) \\
344(3)\end{array}$ & $\begin{array}{l}16(41) \\
32(3) \\
47(0) \\
63(2) \\
78(1)\end{array}$ & $\begin{array}{c}39(45) \\
78(1) \\
118(0) \\
157(0) \\
196(1)\end{array}$ & $\begin{array}{c}43(37) \\
86(8) \\
128(0) \\
171(0) \\
214(2)\end{array}$ & $\begin{array}{c}3 \cdot 2(43) \\
6 \cdot 4(2) \\
9 \cdot 6(0) \\
13(0) \\
16(2)\end{array}$ \\
\hline Agropyron & $\begin{array}{l}723(23) \\
1252(16) \\
1780(7) \\
2309(0) \\
2837(1)\end{array}$ & $\begin{array}{l}64(24) \\
106(12) \\
147(6) \\
189(2) \\
230(3)\end{array}$ & $\begin{array}{c}76(37) \\
151(5) \\
227(4) \\
302(0) \\
378(1)\end{array}$ & $\begin{array}{l}16(35) \\
33(9) \\
49(2) \\
66(0) \\
82(1)\end{array}$ & $\begin{array}{l}11(41) \\
22(5) \\
32(0) \\
43(0) \\
53(1)\end{array}$ & $\begin{array}{l}4(43) \\
7(1) \\
11(1) \\
14(1) \\
18(1)\end{array}$ & $\begin{array}{c}30(26) \\
57(13) \\
83(5) \\
110(2) \\
136(1)\end{array}$ & $\begin{array}{l}5(25) \\
10(17) \\
14(4) \\
19(0) \\
23(1)\end{array}$ \\
\hline Soils & $\begin{array}{c}3743(2) \\
6211(0) \\
8679(0) \\
11147(13) \\
13615(32)\end{array}$ & $\begin{array}{l}137(9) \\
214(12) \\
292(12) \\
369(11) \\
446(3)\end{array}$ & $\begin{array}{l}136(27) \\
228(15) \\
321(4) \\
413(0) \\
506(1)\end{array}$ & $\begin{array}{l}69(27) \\
132(15) \\
196(3) \\
259(1) \\
322(1)\end{array}$ & $\begin{array}{l}23(16) \\
38(14) \\
53(10) \\
68(4) \\
83(3)\end{array}$ & $\begin{array}{l}118(5) \\
169(23) \\
221(11) \\
273(5) \\
324(3)\end{array}$ & $\begin{array}{l}38(32) \\
53(6) \\
68(5) \\
83(2) \\
97(2)\end{array}$ & $\begin{array}{l}2 \cdot 0(4) \\
4.0(0) \\
6.0(17) \\
8.0(20) \\
10(6)\end{array}$ \\
\hline SMBs & $\begin{array}{l}1002(12) \\
1489(14) \\
1977(11) \\
2485(6) \\
2953(4)\end{array}$ & $\begin{array}{l}45(21) \\
79(13) \\
114(7) \\
148(3) \\
182(3)\end{array}$ & $\begin{array}{l}140(39) \\
255(6) \\
371(1) \\
487(0) \\
603(1)\end{array}$ & $\begin{array}{l}77(30) \\
145(13) \\
213(1) \\
281(0) \\
349(3)\end{array}$ & $\begin{array}{l}8(27) \\
14(14) \\
19(4) \\
25(1) \\
31(1)\end{array}$ & $\begin{array}{l}10(31) \\
20(10) \\
31(3) \\
41(2) \\
51(1)\end{array}$ & $\begin{array}{l}E \\
\overline{-} \\
-\end{array}$ & $\begin{array}{l}- \\
\overline{-} \\
-\end{array}$ \\
\hline Hypogymnia & $\begin{array}{c}717(10) \\
965(13) \\
1213(12) \\
1481(6) \\
1709(6)\end{array}$ & $\begin{array}{c}50(21) \\
78(17) \\
106(7) \\
134(1) \\
162(1)\end{array}$ & $\begin{array}{c}65(20) \\
99(18) \\
133(5) \\
168(3) \\
202(1)\end{array}$ & $\begin{array}{c}33(32) \\
66(12) \\
99(2) \\
132(0) \\
164(1)\end{array}$ & $\begin{array}{l}8(5) \\
12(17) \\
15(13) \\
19(8) \\
23(4)\end{array}$ & $\begin{array}{l}16(38) \\
31(7) \\
46(1) \\
61(0) \\
77(1)\end{array}$ & $\begin{array}{l}- \\
E \\
-\end{array}$ & $\begin{array}{l}- \\
\overline{-} \\
=\end{array}$ \\
\hline Tak & $\begin{array}{l}186(9) \\
264(15) \\
342(10) \\
420(8) \\
497(5)\end{array}$ & $\begin{array}{l}10(26) \\
17(8) \\
25(7) \\
33(4) \\
40(2)\end{array}$ & $\begin{array}{c}53(10) \\
79(28) \\
104(8) \\
130(0) \\
156(1)\end{array}$ & $\begin{array}{l}4(16) \\
8(21) \\
11(4) \\
15(2) \\
19(1)\end{array}$ & $\begin{array}{c}3 \cdot 6(44) \\
7 \cdot 2(1) \\
11(0) \\
14(0) \\
18(1)\end{array}$ & $\begin{array}{l}E \\
- \\
-\end{array}$ & $\begin{array}{l}- \\
- \\
-\end{array}$ & $\begin{array}{l}- \\
z \\
-\end{array}$ \\
\hline
\end{tabular}

ESTIMATED CONCENTRATION MAPS (figs 6-8)

The maps of pollution flow show concentrations of $\mathrm{Fe}, \mathrm{Mn}$, and $\mathrm{Cr}$ generally decreasing as distance from the foundry increased, with many of the contours orientated according to the prevailing west-south west wind or in a northerly direction.

GENERAL ANALYSIS OF CONCENTRATIONS

The indigenous samplers collected a wider range of metals than the transplants. All nine metals were found in Hypnum and soils at most sites (table); in Lecanora and grass only Co was missing and in SMBs and Hypogymnia $\mathrm{Co}$ and $\mathrm{Cd}$ were lacking. In each type of sampler a factor of between 3 and 5 separated the top values of the lowest concentration range from the highest values. The metal with the highest concentrations in all samplers was Fe. The concentrations of $\mathrm{Mn}$ and $\mathrm{Zn}$ were usually second or third highest, but in Lecanora, the SMBs, and Hypogymnia the values of $\mathrm{Pb}$ were comparable. Although $\mathrm{Cu}, \mathrm{Cr}$, and $\mathrm{Ni}$ were generally detected in lower concentrations, moderately high values were found in some types of sampler: $\mathrm{Cu}$ in Hypnum, $\mathrm{Cr}$ in soils, and $\mathrm{Ni}$ in Lecanora. The values of $\mathrm{Cd}$ and $\mathrm{Co}$ were consistently the lowest.

In the direct comparison of the concentrations of metals in the various types of sampler the highest values were in soils (where they were around four times higher than those in Lecanora which usually had the second highest values); soils also gave high concentrations of metals other than $\mathrm{Ni}$ and $\mathrm{Pb}$, which were present elsewhere in moderate amounts only. The highest concentrations of $\mathrm{Mn}, \mathrm{Cu}$, and $\mathrm{Pb}$ were found most frequently in Hypnum, which also had relatively high values of $\mathrm{Cr}$. The highest concentrations of $\mathrm{Ni}$ were often found in Lecanora. At many sites, grass showed the highest values of $\mathrm{Cd}$ and relatively high 

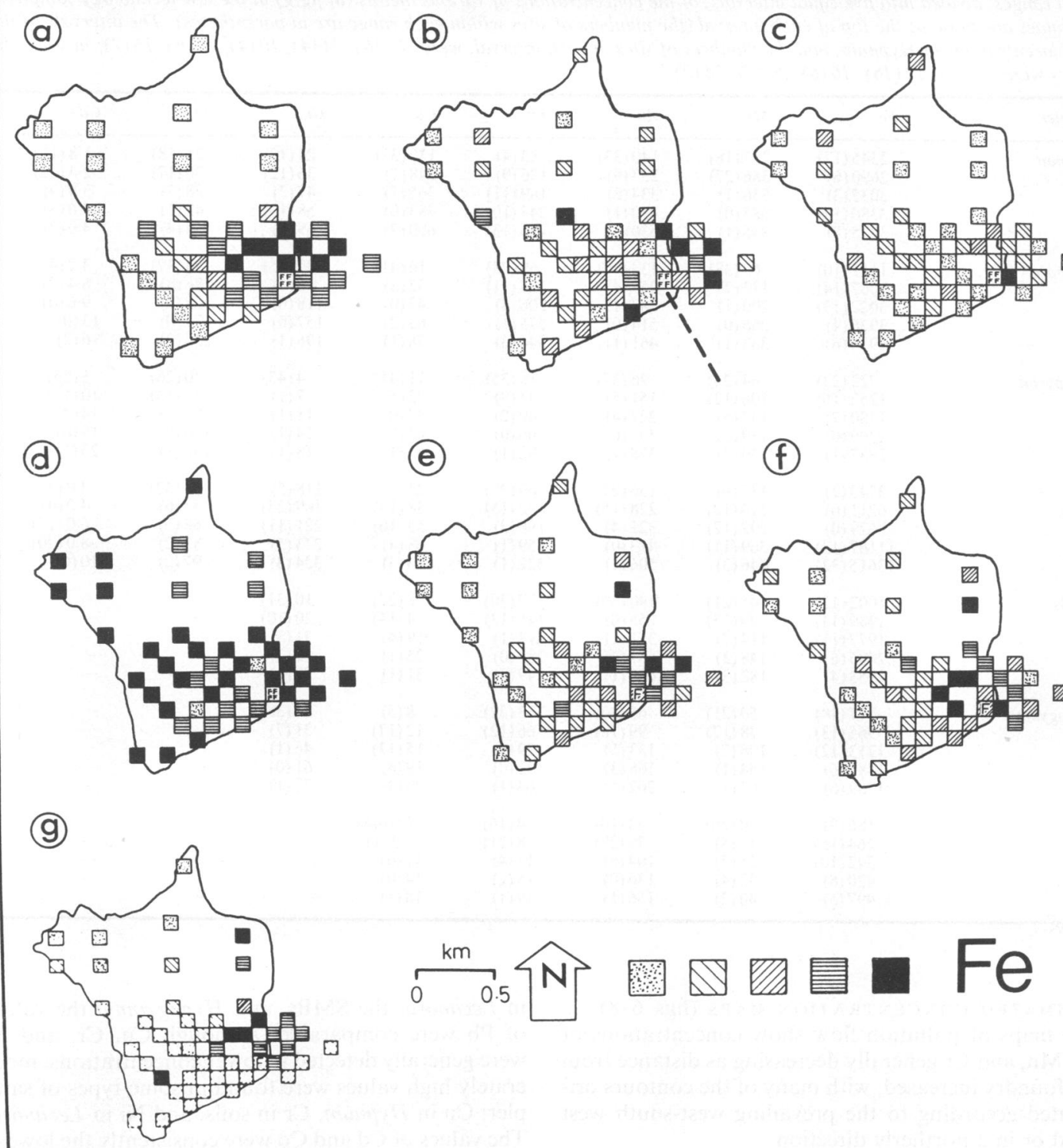

Fig 3 Grid map showing concentrations of Fe in different samplers at sites in Armadale; (a) Hypnum, (b) Lecanora, (c) grass, (d) soils, (e) SMBs, (f) Hypogymnia, (g) tak. Foundry is located in south west corner of town, near top of $\bigcirc$ dotted line. For concentration ranges represented by different types of grid square see legend to table 1 .

values of $\mathrm{Ni}$, but the concentrations of the remaining metals were generally lower than in the other indigenous samplers. Despite the short exposures of the SMBs, these transplants frequently contained the highest values of $\mathrm{Zn}$ and the third highest concentrations of $\mathrm{Fe}$; otherwise, concentrations of the remaining metals were usually lower than in all indige. enous samplers except grass. In Hypogymnia the concentrations of $\mathrm{Pb}$ and $\mathrm{Cr}$ were frequently higher tha those in grass, and the values of $\mathrm{Fe}, \mathrm{Mn}$, and $\mathrm{Zn}$ wege comparable.

In the different types of sampler the mean concen- 


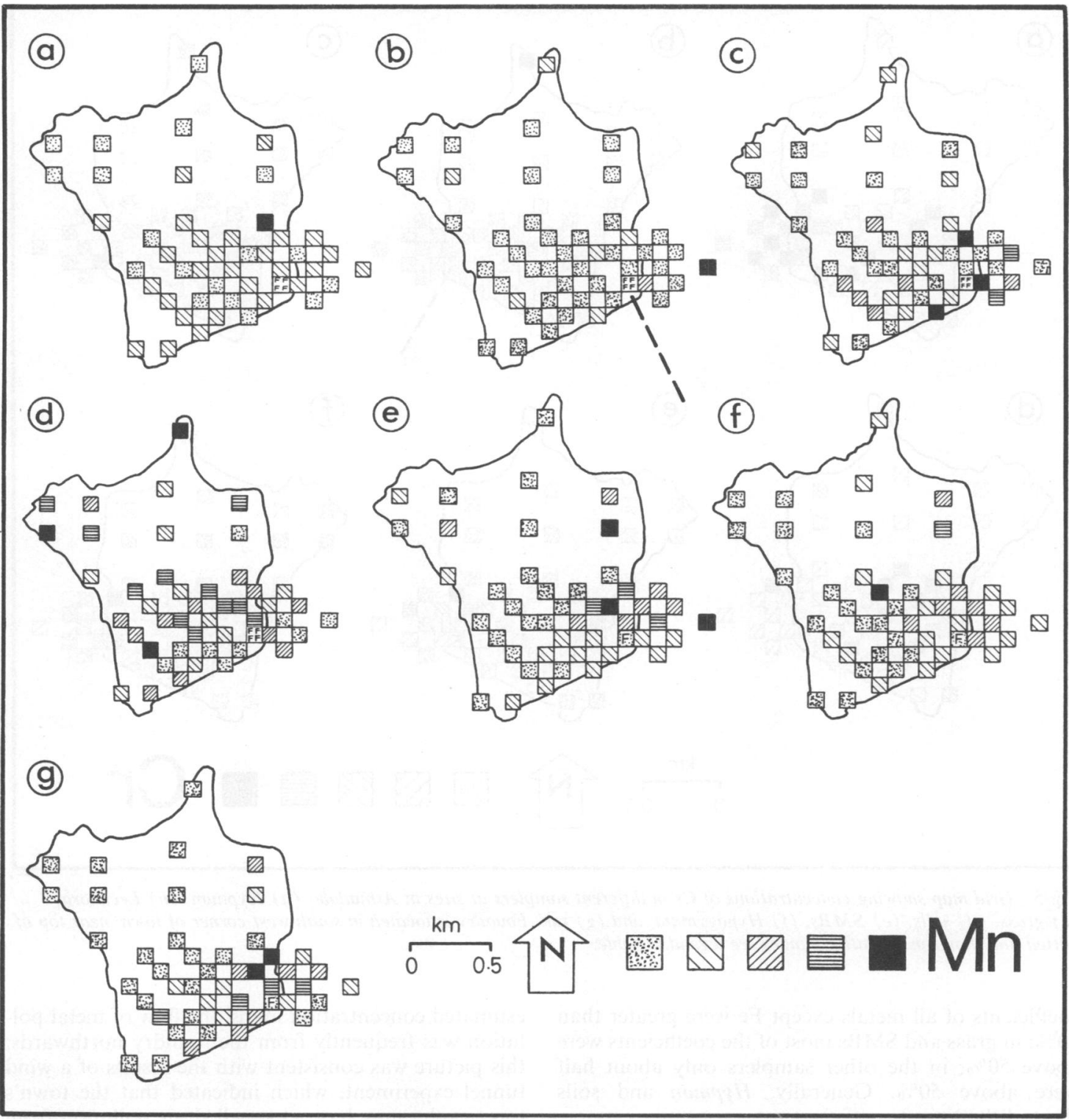

Fig 4 Grid map showing concentrations of Mn in different samplers at sites in Armadale: (a) Hypnum, (b) Lecanora, (c) grass, (d) soils, (e) SMBs, (f) Hypogymnia, and (g) tak. Foundry is located in south west corner of town, near top of dotted line. For concentration ranges see legend to table.

trations of $\mathrm{Fe}$ in the whole town exceeded that of the next most abundant metal by the following factors: $x$ 5 in Hypnum, $\times 20$ in Lecanora, $\times 10$ in grass, $\times 48$ in soils, $\times 14$ in SMBs, $\times 13$ in Hypogymnia, and $\times$ 4 in tak. In the indigenous samplers the mean metal concentrations generally followed the following sequence: $\mathrm{Fe} \gg \mathrm{Mn}>\mathrm{Zn}, \mathrm{Pb}>\mathrm{Ni}, \mathrm{Cu}, \mathrm{Cr}>\mathrm{Cd}$, $\mathrm{Co}$; in the transplants the sequence was: $\mathrm{Fe} \gg \mathrm{Zn}>\mathrm{Mn}, \mathrm{Pb}>\mathrm{Cu}, \mathrm{Cr}>\mathrm{Ni}$.

A comparison of the variability of the concentrations in the different types of sampler showed that the highest coefficients were in Lecanora, where the 


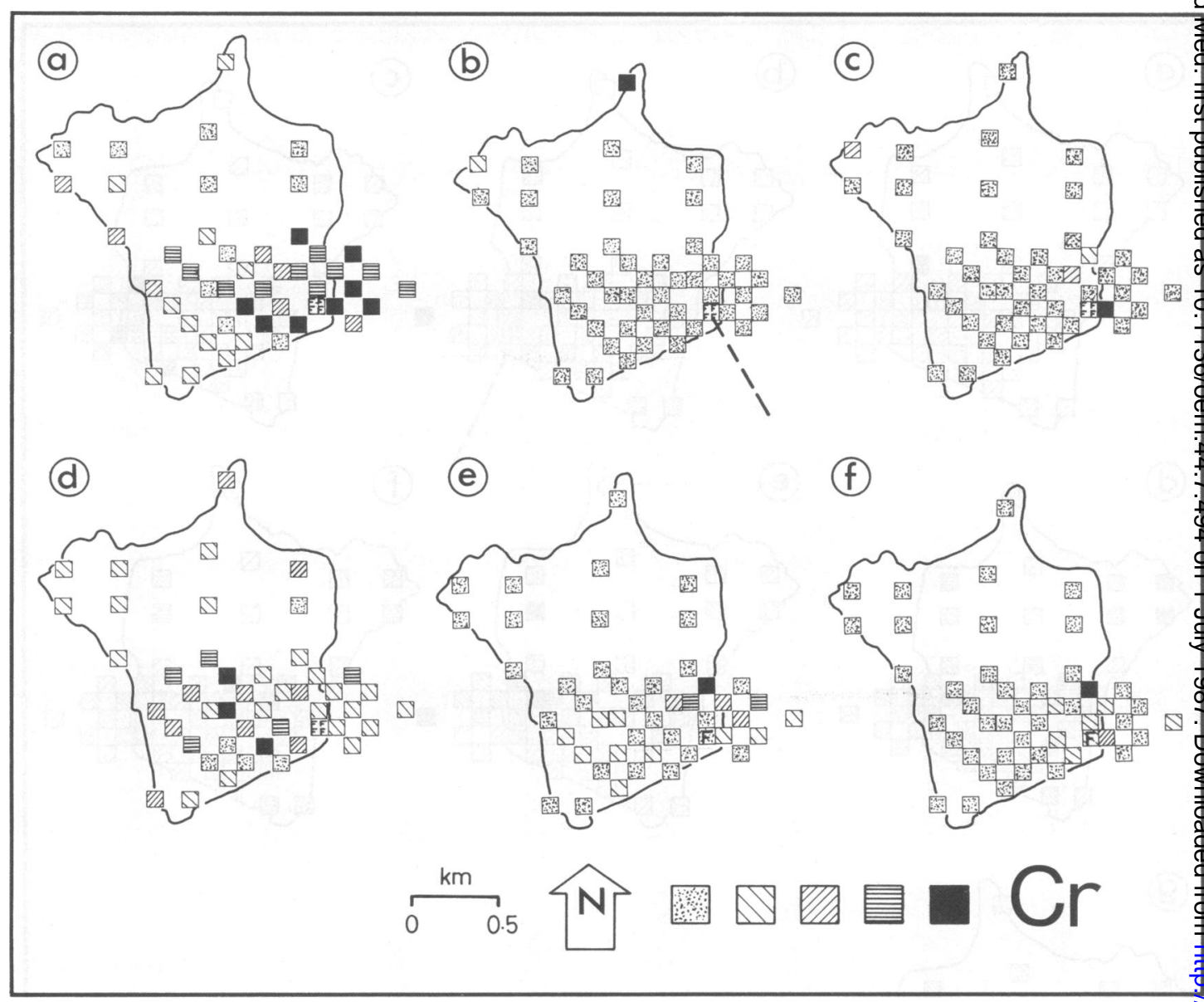

Fig 5 Grid map showing concentrations of $\mathrm{Cr}$ in different samplers at sites in Armadale: (a) Hypnum, (b) Lecanora, (c) grass, (d) soils, (e) SMBs, (f) Hypogymnia, and (g) tak. Foundry is located in south west corner of town, near top of dotted line. For concentration ranges see legend to table.

coefficients of all metals except $\mathrm{Fe}$ were greater than $50 \%$; in grass and SMBs most of the coefficients were above $50 \%$; in the other samplers only about half were above $50 \%$. Generally, Hypnum and soils showed the lowest coefficients.

\section{Discussion}

With all samplers the sites with high concentrations of metals were close to the steel foundry; a smaller zone with high concentrations was found less consistently in the north-north east of Armadale. High values in the latter zone had not been expected because no apparent sources of metals could be found there. These two areas approximated to zones where clustering of lung cancer had been noted: ${ }^{-5}$ On the estimated concentration maps, the flow of metal poos lution was frequently from the foundry northwards: this picture was consistent with the results of a wind tunnel experiment, which indicated that the town topography may have channelled air pollution from the foundry towards the north. ${ }^{20}$ Low concentrations of metals at most of the town's periphery suggestes that pollution from outside the town was negligiblew

The discrepancies between the deposition patterios of the same metal in different types of sampler prodably had several causes. Firstly, having experience्e different durations of exposure, the samplers hate been subject to different environmental conditions and different amounts of metals in the atmosphere. Secondly, the importance of various routes for acc mulating metals differed between samplers-f $\vec{\theta}$ 

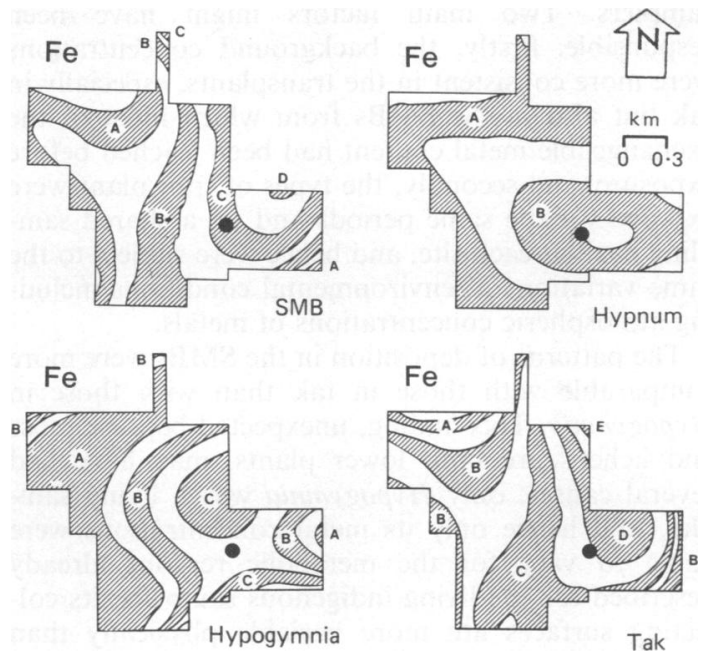

Fig 6 Flow of pollution by $\mathrm{Fe}$ in spherical moss bags (SMBs), Hypogymnia, Hypnum, and tak. Black spot marks approximate position of foundry. Contour bands contain letters of alphabet corresponding to relative concentrations of a metal within any one map, " $A$ " representing lowest concentrations.

example, the atmosphere was uniquely important for the moss and lichens, whereas grass derived metals from both the soil and the atmosphere, and the soils gained metals from all sources in the biosphere. Thirdly, whereas the plant samplers collected metals notably by passive cation exchange, with some metals such as Fe being preferentially taken up, the soils collected all metal particles making contact with them; the grass could also have taken up some metals actively, although the precise importance of this mechanism is unknown. Fourthly, seasonal influences can affect the metal content of the biomonitors, particularly of grass ${ }^{21}$ in which the concentrations of metals decrease during spring as the new growth begins. Fifthly, the concentrations in the four types of sampler would have been differentially affected by environmental influences such as the microclimate, urban pollution, adverse weather conditions such as snow, and any toxic effects of the accumulated metals; beside their toxic effects, air pollutants can alter the amounts of metals in the samplers in other ways-for example, $\mathrm{SO}_{2}$ can lower the $\mathrm{pH}$ of rainwater and its resulting acidity can increase the solubility of metals and thus the extent of their absorption. The moisture content of all samplers, except perhaps the soils, dictates the amounts of metals retained. Finally, slight physical and chemical differences between the samplers' collecting surfaces will affect the types and relative concentrations of metals that are collected and retained.
Because soils and grass have close physical and biological relations, their patterns of metal pollution were expected to be more similar than was found. Several factors may have caused these discrepancies. Firstly, variations in the type of parent rock and soil profiles $^{22}$ and the 47 sites could have reduced the degree of comparability with the other samplers at the same sites; furthermore, although the nutrient uptake by the root systems of grass is likely to cause its metal content to reflect that of the underlying soil, the degree of the grasses' contamination by soil splash could have varied between sites. Secondly, metal concentrations in surface soils may be modified by the type of overlying vegetation: some metals are added from decaying plant material; a dense covering of vegetation inhibits metal collection by the soils, whereas a less dense covering can trap particles which would otherwise have been washed away; root respiration can decrease the soils' $\mathrm{pH}$, thereby enhancing the leaching out of metals; plants' roots can translocate metals in both directions between the plants and the soils. Thirdly, undisturbed surface soils are difficult to find, and cryptic disturbances in the soils of Armadale could have caused some of the variation in their metal concentrations. Fourthly, properties of soil, such as $\mathrm{pH}$, organic content, texture and water content, can alter its metal content. ${ }^{23}$ Finally, micro and macro flora and fauna living in the soil can increase or decrease its metal content, depending on their activities; the effects of these metabolic activities on the metal concentrations in soils must differ from
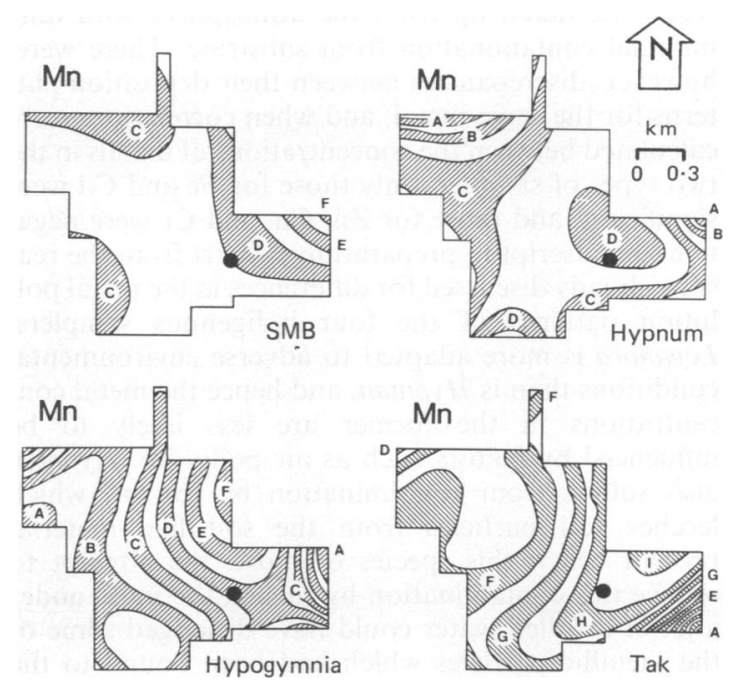

Fig 7 Flow of pollution by Mn in spherical moss bags (SMBs), Hypogymnia, Hypnum, and tak. Black spot marks approximate position of foundry. Contour bands: see fig 6 legend. 

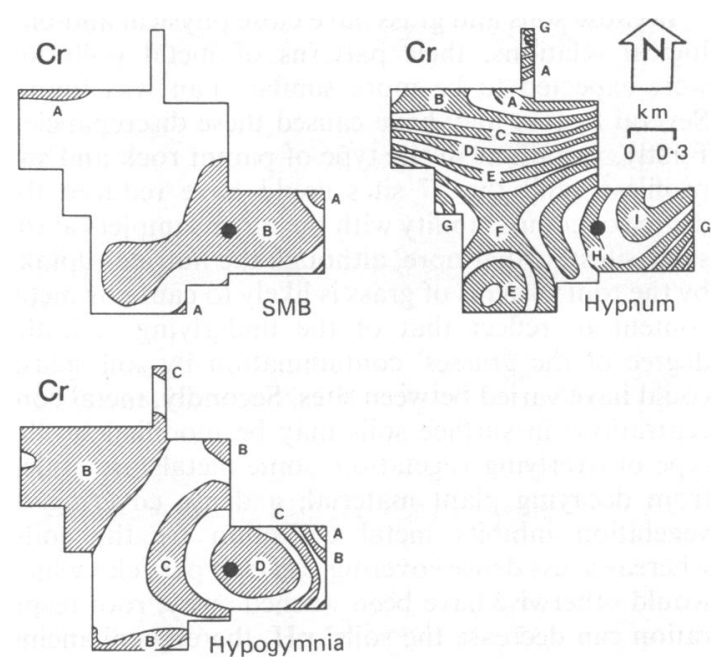

Fig 8 Flow of pollution by $\mathrm{Cr}$ in spherical moss bags (SMBs), Hypogymnia, and Hypnum. No Cr was found in tak. Black spot marks approximate position of foundry. Contour bands: see fig 6 legend.

the effects of the metabolism of individual grass plants on the metal values in the grasses.

The two types of indigenous lower plant, Lecanora and Hypnum, had been expected to show similar patterns of metal deposition: their sampling heights and mechanisms for collecting metals were similar, and both were living and epiphytic so that most metals would be taken up from the atmosphere with only minimal contamination from substrate. There were, however, discrepancies between their deposition patterns for the same metal; and when correlations were calculated between the concentrations of metals in the two types of sampler, only those for $\mathrm{Fe}$ and $\mathrm{Cd}$ were significant, and those for $\mathrm{Zn}, \mathrm{Cu}$, and $\mathrm{Cr}$ were negative (manuscript in preparation). Apart from the reasons already discussed for differences in the metal pollution patterns of the four indigenous samplers, Lecanora is more adapted to adverse environmental conditions than is Hypnum, and hence the metal concentrations in the former are less likely to be influenced by factors such as air pollution. Hypnum also suffers from contamination by run off which leeches soil particles from the soil like material present below this species of moss; the attempt to reduce this contamination by rinsing the moss under a jet of distilled water could have dislodged some of the metallic particles which had been bound to the cells by cation exchange.

Generally, there was a greater comparability between the patterns of deposition in the transplanted samplers than between the patterns in the indigenous samplers. Two main factors might have bee responsible: firstly, the background concentrations were more consistent in the transplants, especially in. tak but also in the SMBs from which most of the exchangeable metal content had been leached before exposure; and secondly, the types of transplant were exposed for the same periods and on a shared same pling head at each site, and hence were subject to the same variations of environmental conditions includes ing atmospheric concentrations of metals.

The patterns of deposition in the SMBs were more comparable with those in tak than with those in Hypogymnia. This finding, unexpected because moss and lichens are both lower plants, may have has several causes: only Hypogymnia was a living samb pler, and hence only its metal concentrations wers liable to vary for the metabolic reasons alreadiy described for the living indigenous samplers; its cot lecting surfaces are more variable physically that those of tak and the SMBs; having been transplante\& directly from its habitat into the field, its background concentrations were less uniform; because it requireg no preparation before being transplanted, its con tamination by metals was probably greater and more variable; its positioning on the sampling heads was a an angle of $45^{\circ}$, whereas the positioning of the $\mathrm{SMB}_{8}$ and tak allowed airborne metals to be collecte equally from all directions; and when the samples of Hypogymnia were removed from their substrates aftei exposure, some of the substrate unavoidablo remained in some samples, causing their cons tamination.

Despite the different ways in which metals are retained in SMBs and tak, the discrepancies betweef their patterns of deposition of a given metal were minor. In tak the particles are entrapped by its mes or adhere to its surface; in the SMBs metallic particles are trapped by the leafy structure of the moss, where many are retained by the mechanism of cation. exchange with its sequence for preferential uptake. ${ }^{28}$ Hence, it was possible that different types of metal and sizes of particle were collected by the two sams plers. Furthermore, the concentrations of metals cob lected by Sphagnum depend greatly on its moisture. content, which may explain why the concentrations of most metals in the SMBs increased with the decreasing temperatures, when there is less evapos ration (manuscript in preparation). Tak has a morહ uniform collecting surface and a more consistent prछ exposure concentration; its extremely sticky surfaes was likely to collect particles from any object touched, increasing the chance of accidental metap contamination; on the other hand, some of the part ticles adhering to its surface may have been dislodge when the tak samplers were rolled before being fitte into the digestion flasks for chemical analysis. 
The long exposure time of soils and their function as the ultimate sink of pollution led to the highest concentrations of metals being found in them, and also contributed to the relatively high values at sites at the town's periphery. A long exposure was probably also a factor underlying the comparatively high concentrations in the indigenous moss (Hypnum) and indigenous lichen (Lecanora); other factors include their potential for collecting high concentrations of metals through their high cation exchange capacities, the enhancement of this cation exchange through their retention of moisture, their proportionately large surface areas in comparison with those of grass, their efficient methods as epiphytes for accumulating atmospheric nutrients, the absence of a surface barrier such as a waxy cuticle, and their relative tolerance of urban pollution (unhealthy samplers collect lower concentrations of metals) and of other adverse environmental conditions such as drought.

Of the indigenous samplers grass collected the lowest concentrations of most metals. Although Agropyron has advantages for the sampling of airborne metals in comparison with other types of higher plants, ${ }^{11}$ its efficiency at collecting metals was demonstrably less than that of the lower plants; also, because only its current growth could be collected, its sampling time was under two years.

The transplanted samplers generally contained lower concentrations of metals than did the indigenous samplers, because their exposure time had been shorter. Nevertheless, relatively high values of some metals, particularly $\mathrm{Pb}$, were found in SMBs. Probable reasons for such comparatively high concentrations, despite the relatively short exposures of SMBs, come under the headings of capture and retention. Firstly, Sphagnum has many properties facilitating the capture of metal particles: the large proportion of its dry weight contributed by leaves of unicellular thickness allows a large surface area per unit weight ${ }^{25}$; the spiral arrangement of the leaves around the stems and the presence of cell pores with a diameter of 5-15 $\mu \mathrm{m}$ enhance the entrapment of particles. Secondly, the mechanisms for retaining metal particles in Sphagnum are highly effective: it has the greatest proportion, by weight, of cation exchange sites of all plants ${ }^{25}$; it can have a high water volume (20 $\times$ its structural weight); having been acid washed, its low $\mathrm{pH}$ also facilitates cation exchange, and most of its cation exchange sites are available for the uptake of metals; and it absorbs cations efficiently from dilute solutions such as rain water.

In conclusion, therefore, the results from the use of seven types of low technology sampler in Armadale were in agreement in showing that the main zone of pollution was near the foundry, but that a smaller zone was present in the north of the town. The dis- crepancies between the deposition patterns of metals in the samplers probably arose from differences in several factors: the duration of exposure to Armadale's atmosphere, the methods of metal uptake and retention, the sampling heights, the sensitivities to environmental toxicity, the sources of the metals, the vulnerability to accidental contamination, and the directions of airflow at which the collection of particles was maximal. For similar environmental surveys in future, therefore, the choice of types of sampler will depend on the nature of the pollutants and on whether interest is concentrated on historical or current patterns of pollution.

The correlations between the concentrations of the metals in the samplers, and the relation between the concentrations and various environmental factors, will be described elsewhere.

Work in the Environmental Epidemiology and Cancer Centre was mainly supported by grants provided by the Scottish Home and Health Department. This research forms part of a PhD thesis by F A Gailey (nee Yule). Help from the following is gratefully acknowledged: $\mathrm{Mr} \mathbf{J}$ Hotson and $\mathrm{Mr} \mathrm{T}$ Waugh of Edinburgh University for advice in computer mapping; Professor C du V Florey of the Department of Community Medicine, Dundee University, for his helpful criticism; $\mathrm{Mr} \mathrm{S}$ Ogston of the same department for statistical advice; Mr G Smith of the Environmental Epidemiology and Cancer Centre for laboratory work; Miss Laura Rintoul and Mr A High of the same centre for help in checking data; $\mathrm{Mr} \mathrm{J}$ Burgoyne, Armadale's housing officer, and Armadale's householders for cooperating in the study; $\mathrm{Mr}$ W Ferrier of the Amalgamated Union of Engineering Workers for his help; and staff at Rosebank Nursery, Livingston, for meteorological information.

\section{References}

1 Lloyd OLL, Barclay R. Hypothesis: a short latent period for respiratory cancer in a susceptible population. Community Medicine 1979;1:210-20.

2 Lloyd OLL, MacDonald J. Continuous epidemiological mapping - a needed public health watchdog. Public Health 1984;98:321-6.

3 Lloyd OLL, Barclay R, Lloyd MM. Armadale group practice. Lung cancer and other health problems in a Scottish industrial town; a review. Ambio 1985;14:322-8.

4 Lloyd OLL, Williams FLR, Gailey FA. Is the Armadale epidemic over? Air pollution and mortality from lung cancer and other diseases, 1961-82. Br J Ind Med 1985;42:815-23.

5 Lloyd OLL. Respiratory cancer clustering associated with localized industrial air pollution. Lancet 1978; i:318-20.

6 Lloyd OLL, Sclare G, Lloyd MM, Yule FA. Respiratory cancer in a Scottish community: some pathological, occupational, and general environmental considerations. In: Grundmann E, Clemmesen J, Muir CS, eds. Cancer campaign 6, cancer epi- 
demiology. Stuttgart: Gustav Fischer Verlag, 1982:103-14.

7 Lloyd OLL, Ireland E, Tyrrell HKM, Williams FLR. Respiratory cancer in a Scottish industrial community: a retrospective case-control study. J Soc Occup Med 1986;36:2-8.

8 Goodman GT, Smith S, Inskip MJ. Report of a collaborative study on certain elements in air, soil, plants, animals and humans in the Swansea-Neath-Port Talbot area. Cardiff: Welsh Office, 1975.

9 Martin MH, Coughtrey PJ. Biological monitoring of heavy metal pollution. London: Applied Science, 1982.

10 Yule FA, Lloyd OLL. An index of atmospheric pollution survey in Armadale, central Scotland. Water, Air Soil Pollution 1984:22:27-45.

11 Gailey FA, Lloyd OLL. Grass and surface soils as monitors of atmospheric metal pollution in central Scotland. Water, Air Soil Pollution 1985;24:1-18.

12 Gailey FA, Lloyd OLL. Methodological investigations into low technology monitoring of atmospheric metal pollution, part 1 . Environmental Pollution 1986;12:41-59.

13 Gailey FA, Lloyd OLL. Methodological investigations into low technology monitoring of atmospheric metal pollution, part 2. Environmental Pollution 1986;12:61-74.

14 Gailey FA, Lloyd OLL. Methodological investigations into low technology monitoring of atmospheric metal pollution, part 3 . Environmental Pollution 1986;12:85-109.

15 Yule FA, Lloyd OLL. Metal content of an indigenous moss in Armadale, central Scotland. Water, Air Soil Pollution 1984;211:261-70.

16 Yule FA, Lloyd OLL. Low technology monitoring of air pollution by metals in relation to the geography of lung cancer. In:
Sunderman $\mathrm{FW} \mathrm{Jr}$, ed. Nickel in the human environment. Lyo $\vec{R}$ International Agency for Research on Cancer, 1984:253-6\$ (IARC scientific publ No 53.)

17 Gailey FA, Lloyd OLL. The use of Lecanora conizaenides as monitor of the distribution of atmospheric pollution by metals Ecology of Disease 1983;2:215-24.

18 Gailey FA, Lloyd OLL. Metal deposition patterns in Centr尔 Scotland as determined by lichen transplants. Environment Monitoring and Assessment 1985;5:291-309.

19 Gailey FA, Lloyd OLL. Atmospheric metal pollution in a con munity monitored by spherical moss bags. Environmentad Health Perspectives 1986;68:187-96.

20 Gailey FA, Lloyd OLL. A wind tunnel study of the flow of $\overrightarrow{a i b}$ pollution in Armadale, central Scotland. Ecology of Disease 1983;2:419-31.

21 Tjell JC, Hovmand MF, Mosbaek H. Atmospheric lead pollution of grass grown in a background area in Denmark. NatuR 1979;280:425-6.

22 Davies BE, Roberts LJ. The distribution of heavy metal comtaminated soils in North East Clwyd, Wales. Water, Air So Pollution 1978;9:507-18.

23 Andersson A. Heavy metals in Swedish soils: on their retentioit distribution and amounts. Swedish Journal of Agriculturq Research 1977;7:7-20.

24 Pucket KJ, Nieboer D, Gorzynski MJ, Richardson DHS. The uptake of metal ions by lichens: a modified ion exchange process. New Phytologist 1973;72:329-42.

25 Clymo RS. Ion exchange in Sphagnum and its relation to bog ecology. Annals of Botany 1963;27:309-24. 